\title{
BMJ Open Hypertension, cardiovascular disease and cause of death in Danish living kidney donors: matched cohort study
}

\author{
Mavish Chaudry (10 , ${ }^{1}$ Gunnar Hilmar Gislason, ${ }^{1}$ Emil Loldrup Fosbøl, ${ }^{2}$ Lars Køber, ${ }^{2}$ \\ Thomas Alexander Gerds, ${ }^{3}$ Christian Torp-Pedersen ${ }^{4}$
}

To cite: Chaudry M, Gislason GH, Fosbøl EL, et al. Hypertension, cardiovascular disease and cause of death in Danish living kidney donors: matched cohort study. BMJ Open 2020;10:e041122. doi:10.1136/ bmjopen-2020-041122

- Prepublication history and additional materials for this paper is available online. To view these files, please visit the journal online (http://dx.doi. org/10.1136/bmjopen-2020041122).

Received 03 June 2020 Revised 03 September 2020 Accepted 24 September 2020

\section{Check for updates}

(C) Author(s) (or their employer(s)) 2020. Re-use permitted under CC BY-NC. No commercial re-use. See rights and permissions. Published by BMJ.

${ }^{1}$ Copenhagen Cardiovascular Research Center, HerlevGentofte Hospital University of Copenhagen, Hellerup, Denmark

${ }^{2}$ The Heart Centre,

Rigshospitalet University of Copenhagen, Copenhagen, Denmark

${ }^{3}$ The Danish Heart Foundation, Copenhagen, Denmark

${ }^{4}$ Department of Cardiology and Clinical Research, Nordsjællands Hospital, Hillerød, Denmark

Correspondence to

Dr Mavish Chaudry;

mavish89@hotmail.com

\section{ABSTRACT}

Objectives We aimed to investigate the long-term absolute risk of hypertension and cardiovascular disease after kidney donation in living kidney donors.

Design Living kidney donors were matched to 10 controls from the general population.

Setting Multiple Danish national registries were used to identify living kidney donors from 1 January 1996 to 31 December 2017 nationwide.

Participants 1262 living kidney donors and 12620 controls.

Main outcome measures Hypertension, cardiovascular disease and diabetes.

Results The median age of living kidney donors was 52 (men 43\%). Hypertension developed in 50 (4\%) and 231 $(1.8 \%)$ with a median follow-up of 7 years (IQR 3.3-12.1 years with a maximum follow-up of 22 years) and 6.9 years (IQR 3.2-11.7 years and maximum follow-up of 22 years) for donors and controls, respectively. The absolute risk of hypertension was $2.3 \%(95 \% \mathrm{Cl} 1.4 \%$ to $3.2 \%)$ and $1.2 \%(95 \% \mathrm{Cl} 1.0 \%$ to $1.4 \%), 4.2 \%(95 \% \mathrm{Cl} 2.8 \%$ to $5.7 \%$ ) and $2.4 \%$ (95\% Cl $2.1 \%$ to $2.8 \%), 8.6 \%(95 \% \mathrm{Cl}$ $6.0 \%$ to $11.3 \%)$ and $3.3 \%(95 \% \mathrm{Cl} 2.8 \%$ to $3.8 \%)$ within $5,10,15$ years for donors and controls, respectively. The ratio of the 10-year absolute risks for hypertension was 1.64 (95\% Cl 1.44 to 1.88) for donors compared with the controls. Two donors and four controls developed renal replacement therapy requiring end-stage renal disease during follow-up. The absolute risk of cardiovascular disease and diabetes was $7.3 \%(95 \% \mathrm{Cl} 5.7 \%$ to $9.5 \%)$ and $8.3 \%(95 \% \mathrm{Cl} 7.7 \%$ to $9.0 \%), 1.7 \%(95 \% \mathrm{Cl} 0.7 \%$ to $2.8 \%)$ and $3.2 \%(95 \% \mathrm{Cl} 2.7 \%$ to $3.6 \%)$ at 10 years for donors and controls, respectively.

Conclusions Living kidney donors have an increased long-term absolute risk of hypertension compared with controls from the general population.

\section{INTRODUCTION}

Kidney transplantation has expanded worldwide since the first kidney transplantation in $1954 .^{1}$ Living donor kidney transplantation is the preferred treatment of choice in most end-stage renal disease patients as the outcomes as patient and graft survival are better with living kidney donation. ${ }^{2}$ The risk of end-stage kidney disease after living kidney donation is comparable to the general

\section{Strengths and limitations of this study}

This study is limited by the observational design.

- Data on body mass index (BMI), smoking, family history and blood pressure were not available.

- The registries applied in the present study are nationwide, the follow-up was complete and long term every patient record was assessed on individual lev$\mathrm{el}$, and the registry used to track the drugs administered in the treatment of hypertension is accurate and valid.

- The study includes a risk of observation bias. Many patients with hypertension are unaware of their disease, and kidney donors could be more aware and more often have their blood pressure controlled.

population in older studies, whereas recent studies report an increased risk of end-stage kidney disease after living kidney donation as compared with their healthy matched controls. $^{3-6}$ The life expectancy after living kidney donation seems to be similar to the general population. ${ }^{3578}$ The available data on the risk of hypertension are highly variable in living kidney donors after kidney donation and have been reported in the range of $16.3 \%-57 \%$ with mean follow-up between 6.2 and 16.6 years in the studied populations of kidney donors. ${ }^{3-12}$ The present evidence on the risk of hypertension in kidney donors is either characterised by small study populations, single-centre studies, insufficient data on living kidney donors at baseline or during follow-up, dated study populations or reference populations assembled and followed in time periods different from the living kidney donor populations. ${ }^{3-1113}$

The current study aimed to investigate and clarify the long-term absolute risk of hypertension, occurrence of end-stage kidney disease, cardiovascular disease, diabetes and cause of death in a nationwide population of living kidney donors after kidney donation. 


\section{MATERIALS AND METHODS}

\section{Data sources}

All residents in Denmark are provided with a permanent personal identification number at birth or immigration that allows linkage between nationwide administrative registries at individual level. Four of these registries were accessed to retrieve data. The Danish National Patient Registry contains information on all hospital admissions, outpatient appointments, diagnoses and procedural codes since 1978. Each hospital admission and outpatient appointment is at discharge or end of appointment coded with one primary diagnosis, and if appropriate one or more secondary diagnosis according to the International Classification of Diseases (ICD) - until 1994, the eight revision was used (ICD-8), and from 1994, the 10th revision (ICD-10) was applied. ${ }^{14}$ The codes used for accessing comorbidities are considered valid. ${ }^{15}$ The procedural codes are registered according to The Nordic MedicoStatistical Committee Classification of Surgical Procedures since 1996. The National Civil Registry comprises information on vital status for all residents in Denmark within 2 weeks from death. The Danish National Prescription Registry was established in 1995 and contains information on every dispensed prescription in Denmark including date of purchase and package size coded according to the Anatomic Therapeutic Classification system. The registry is considered accurate and valid. ${ }^{16}$ The Danish Registry of Causes of Death holds information on cause of death in all deceased residents in Denmark on individual level since 1970 —coded according to ICD-10 from $1994 .{ }^{17}$

\section{Population}

The Danish National Patient Registry was accessed to identify living kidney donors in the period from 1 January 1996 to 31 December 31 2017. The donors were identified according to hospital admission with following procedural codes: KYKA00, KYKA01, KKAC00, KKAC01. Patients were excluded, if one or more secondary diagnoses related to the nephrectomy were coded at discharge during the admission for nephrectomy (see online supplemental table 1). Finally, each patient was cross-linked in pairs with a living kidney transplant recipient by transplanting hospital and date of kidney transplantation for confirmation of the identified living kidney donor population. The living kidney transplant recipients were identified in the period from 1 January 1996 to 31 December 2017 according to the hospital admission with the discharge procedural code KKAS20 as recorded in The Danish National Patient Registry. The controls were retrieved from the general population in the period from 1 January 1996 to 31 December 2017. Renal replacement therapy requiring end-stage kidney disease, diabetes, cardiovascular disease and hypertension was not allowed for controls at index.

\section{Renal function}

All available serum creatinine measurements for living kidney donors between 1996 and 2017 were included from hospital laboratories in three counties of Denmark and the General Practitioner Laboratory of Copenhagen. Serum creatinine measurements were available for a subset of the living kidney donors and more than one serum creatinine measurement was available in 845 $(67 \%)$ living kidney donors at any given point in time during follow-up. The estimated glomerular filtration rate (eGFR) was calculated using the Chronic Kidney Disease Epidemiology Collaboration equation.

\section{Outcome}

The main outcome of interest was hypertension in living kidney donors after kidney donation in the period 19962017. Hypertension was defined as a combination of at least two of the following drugs used in the treatment of hypertension as registered in the Danish National Prescription Registry with the Anatomic Therapeutic Classification: $\alpha$ adrenergic blockers (C02A, C02B, C02C), non-loop diuretics (C02DA, C02L, C03A, C03B, C03D, C03E, C03X, C07C, C07D, C08G, C09BA, C09DA, C09XA52), vasodilators (C02DB, C02DD, C02DG, C04, $\mathrm{C} 05), \beta$ blockers $(\mathrm{C} 07)$, calcium channel blockers $(\mathrm{C} 07 \mathrm{~F}$, C08, C09BB, C09DB) and renin-angiotensin system inhibitors (C09). This definition has been validated in a previous randomly selected cohort in the Danish population and reached a positive predictive value of $80 \%$ for predicting hypertension, when treated with two drugs used in the treatment of hypertension. ${ }^{18}$ The subjects were followed until event, death or study end. Information on cardiovascular disease and diabetes was derived from The Danish National Patient Registry from index to event, death or study end. The diagnoses of diabetes were additionally augmented as redemption of antidiabetic drug prescriptions with the Anatomic Therapeutic Classification A10 as recorded in The Danish National Prescription Registry (see online supplemental table 1). The date of death and cause of death were retrieved from The National Civil Registry and The Danish Registry of Causes of Death, respectively. Renal replacement therapy was identified as receiving the procedure of dialysis for at least 90 days and 12 times or receiving the procedure of kidney transplantation as registered in The Danish National Patient Registry ${ }^{19}$ (see online supplemental table 1).

\section{Statistical analyses}

Continuous variables were presented as mean $\pm \mathrm{SD}$ or median with IQR. The eGFR measurements were presented as spaghetti diagram. Paired t-test was performed to test for difference in eGFR measurements at 1-year and 10-year follow-up compared with the baseline eGFR measurements. Reverse Kaplan-Meier was used to estimate median follow-up. The living kidney donors were matched with 10 controls from the general population at the date of the donation, birthyear and sex. The Aalen-Johansen method was used to estimate the absolute risk of hypertension, cardiovascular disease, diabetes and renal replacement therapy accounting for the competing 


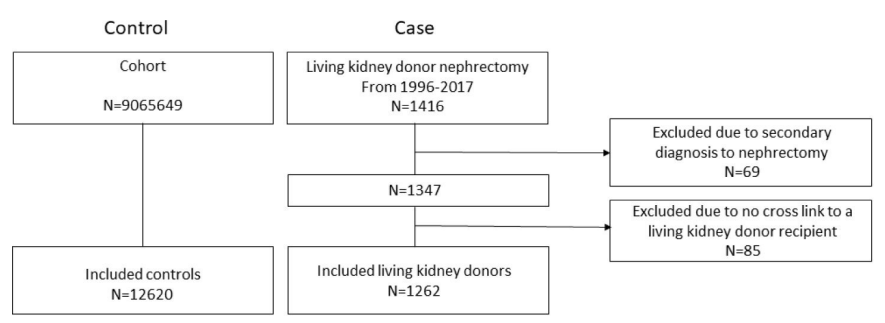

Figure 1 Flowchart.

risk of death. Gray's test was performed to test for differences in absolute risk between cases and matched controls. We also reported the ratio of the 10 -year risks of hypertension comparing cases and matched controls. Living kidney donors with hypertension at index were excluded from the analyses of hypertension. Log rank test was applied to test for difference in overall mortality between cases and matched controls. The statistical analyses were performed using R V.3.6.1.

\section{Patient and public involvement}

Patients or the public were not involved in the study.

\section{RESULTS}

From 1 January 1996 to 31 December 31 2017, a total number of 1262 were identified as living kidney donors, figure 1. Of these, $33(2.6 \%)$ had hypertension at the time of kidney donation. A total of 12620 controls were included in the study. The median age in the living kidney donors was 52 years (IQR 44-60 years), and 538 (43\%) were men. The median age in the controls was 52 years (IQR 44-60), and 5380 (43\%) were men (table 1).

\section{Hypertension}

The median follow-up for hypertension was 7 years (IQR $3.3-12.1$ years with a maximum follow-up of 22 years) and 6.9 years (IQR 3.2-11.7 years and maximum follow-up of 22 years) for donors and controls, respectively.

Hypertension was defined as a combination of two drugs used in the treatment of hypertension. At kidney donation, $87(7 \%)$ living kidney donors were treated with one drug used in the treatment of hypertension with the following distribution: non-loop diuretic 23 (1.8\%), calcium channel blockers 29 (2.3\%), $\alpha$ adrenergic

Table 1 Baseline characteristics of the study population

Living kidney Control donor $(n=1262) \quad(n=12620)$

\begin{tabular}{lcc}
\hline Age (years, median, IQR) & $52(44-60)$ & $52(44-60)$ \\
Male & $538(43 \%)$ & $5380(43 \%)$ \\
Hypertension & $33(2.6 \%)$ & 0 \\
Cancer & 0 & $120(1 \%)$ \\
Diabetes & 0 & 0 \\
Cardiovascular disease & $2(0.2 \%)$ & 0 \\
\hline
\end{tabular}

Values are given as $\mathrm{N}(\%)$. blockers $\leq 3(\leq 0.2 \%), \beta$ blockers $12(0.9 \%)$, renin-angiotensin system inhibitors $22(1.8 \%)$.

During the follow-up period, 50 (4\%) living kidney donors and $231(1.9 \%)$ controls developed hypertension and were treated with different combinations of drugs used in the treatment of hypertension (table 2). Six of the living kidney donors were in treatment with one drug used in treatment of hypertension at kidney donation. The absolute risk of hypertension was $2.3 \%(95 \%$ CI $1.4 \%$ to $3.2 \%$ ) and $1.2 \%$ (95\% CI $1.0 \%$ to $1.4 \%$ ) at 5 years; $4.2 \%$ (95\% CI $2.8 \%$ to $5.7 \%$ ) and $2.4 \%$ (95\% CI $2.1 \%$ to $2.8 \%$ ) at 10 years; $8.6 \%$ (95\% CI $6.0 \%$ to $11.3 \%$ ) and $3.3 \%$ (95\% CI $2.8 \%$ to $3.8 \%$ ) at 15 years for donors and controls, respectively (figure 2). The absolute risk of hypertension in living kidney donors was higher than the matched controls, $\mathrm{p}<0.001$. The absolute risk ratio for hypertension was 1.64 (95\% CI 1.44 to 1.88 ) for living kidney donors compared with the matched controls at 10 years after living kidney donation.

\section{Other comorbidities}

Cardiovascular disease occurred in $82(6.5 \%)$ donors and $899(7.1 \%)$ controls during follow-up. Diabetes was observed in 25 (2\%) donors and 361 (2.9\%) controls during the study period. The absolute risk of cardiovascular disease was $7.3 \%$ (95\% CI $5.7 \%$ to $9.5 \%$ ) and $8.3 \%$ (95\% CI $7.7 \%$ to $9.0 \%$ ) at 10-year follow-up for donors and controls, respectively (figure 3 ). The absolute risk for diabetes was $1.7 \%$ (95\% CI $0.7 \%$ to $2.8 \%$ ) in donors and $3.2 \%$ (95\% CI $2.7 \%$ to $3.6 \%$ ) in controls at 10 years (figure 4). There was no significant difference for cardiovascular disease $(\mathrm{p}=0.37)$ and diabetes $(\mathrm{p}=0.07)$ between the donors and the controls during follow-up, respectively.

\section{Cause of death}

In the observation period, $30(2.4 \%)$ living kidney donors and $423(3.4 \%)$ controls died, $\mathrm{p}=0.001$. The causes of death in the living kidney donors were in descending frequency malignancy $(14 / 1.1 \%)$, gastrointestinal bleeding $(3 / 0.2 \%)$, pneumonia $(\leq 3 / \leq 0.2 \%)$, cardiovascular disease $(\leq 3 / \leq 0.2 \%)$, status asthmaticus $(\leq 3 / \leq 0.2 \%)$, neuromuscular disease $(\leq 3 / \leq 0.2 \%)$ and unknown in six kidney donors. The causes of death in controls were malignancy $(224 / 1.8 \%)$, cardiovascular disease $(68 / 0.5 \%)$, liver cirrhosis $(20 / 0.1 \%)$, chronic obstructive lung disease and respiratory insufficiency $(16 / 0.1 \%)$, neuromuscular disease $(17 / 0.1 \%)$, suicide $(12 / 0.1 \%)$, pneumonia $(8 / 0.06 \%)$, sepsis $(4 / 0.03 \%)$, diabetes $(\leq 3 / \leq 0.02 \%)$, acute abdomen $(\leq 3 / \leq 0.02 \%)$, gastrointestinal bleeding $(\leq 3 / \leq 0.02 \%)$, acute kidney insufficiency $(\leq 3 / \leq 0.02 \%)$ and unknown in $49(0.4 \%)$ controls.

\section{Renal replacement therapy}

Less than three living kidney donors and four controls developed renal replacement therapy requiring end-stage renal disease during follow-up, $\mathrm{p}=0.29$. Less than three controls received a kidney transplant in the study period. 
Table 2 Drug combinations used for living kidney donors and controls in treatment of hypertension developed during followup

Drugs used in the treatment of hypertension

\begin{tabular}{lc}
$\begin{array}{l}\text { Living kidney } \\
\text { donor }(\mathbf{n}=\mathbf{5 0 )}\end{array}$ & $\begin{array}{l}\text { Control } \\
(\mathbf{n}=\mathbf{2 3 1})\end{array}$ \\
\hline $12(24)$ & $107(46)$ \\
$5(10)$ & $15(6)$ \\
$6(12)$ & $9(4)$ \\
$4(8)$ & $21(9)$ \\
$7(14)$ & $11(5)$ \\
$7(14)$ & $22(10)$ \\
$\leq 3(\leq 6)$ & $\leq 3(\leq 1)$ \\
$4(8)$ & $16(7)$ \\
$3(6)$ & $23(10)$ \\
$\leq 3(\leq 6)$ & - \\
- & $\leq 3(\leq 1)$ \\
- & $4(2)$
\end{tabular}

Non-loop diuretica and renin-angiotensin system inhibitors

Non-loop diuretica and $\beta$ blockers

Non-loop diuretica and calcium channel blockers

$\beta$ blockers and renin-angiotensin system inhibitors

Calcium channel blockers and $\beta$ blockers

Calcium channel blockers and renin-angiotensin system inhibitors

$\alpha$ adrenergic blockers and renin-angiotensin system inhibitors

Non-loop diuretica, renin-angiotensin system inhibitors and $\beta$ blockers

Non-loop diuretica, renin-angiotensin system inhibitors and calcium channel blockers

Non-loop diuretica, $\beta$ blockers and calcium channel blockers

Renin-angiotensin system inhibitors, $\beta$ blockers and calcium channel blockers

Non-^loop diuretica, renin-angiotensin system inhibitors, $\beta$ blockers and calcium channel blockers

- , none.

*Values are given as $\mathrm{N}(\%)$.

\section{Renal function}

The eGFR $\left(\right.$ mean \pm SD) was $89.4 \pm 16.7 \mathrm{~mL} / \mathrm{min} / 1.73 \mathrm{~m}^{2}$ and age (median, IQR) was 55, 45-62 years $(\mathrm{n}=812)$, $59.4 \pm 13.1 \mathrm{~mL} / \mathrm{min} / 1.73 \mathrm{~m}^{2}$ and age (median, IQR) was $56,46-64$ years $(\mathrm{n}=410), 65.4 \pm 15.2 \mathrm{~mL} / \mathrm{min} / 1.73 \mathrm{~m}^{2}$ and age (median, IQR) was $63,54-71$ years $(n=145)$ at baseline, 1-10 years after living kidney donation, respectively. The change in eGFR was significant at 1 -year $(n=560)$ and 10-year $(n=68)$ follow-up compared with baseline eGFR, $\mathrm{p}<0.0001$ (figure 5).



Figure 2 Absolute risks of hypertension after living kidney donation. * $P$ value indicates the difference in absolute risks by Gray's test.

\section{DISCUSSION}

In this nationwide study of living kidney donors with complete and long-term follow-up in the period 19962017, the long-term absolute risk of hypertension was higher in the living kidney donors than the matched controls from the general population.

\section{Comparison with other studies}

Previous studies have addressed the prevalence of hypertension in living kidney donors. ${ }^{3-11}$ Sanchez et al analysed a series of 3700 living kidney donors during 1963-2014 at

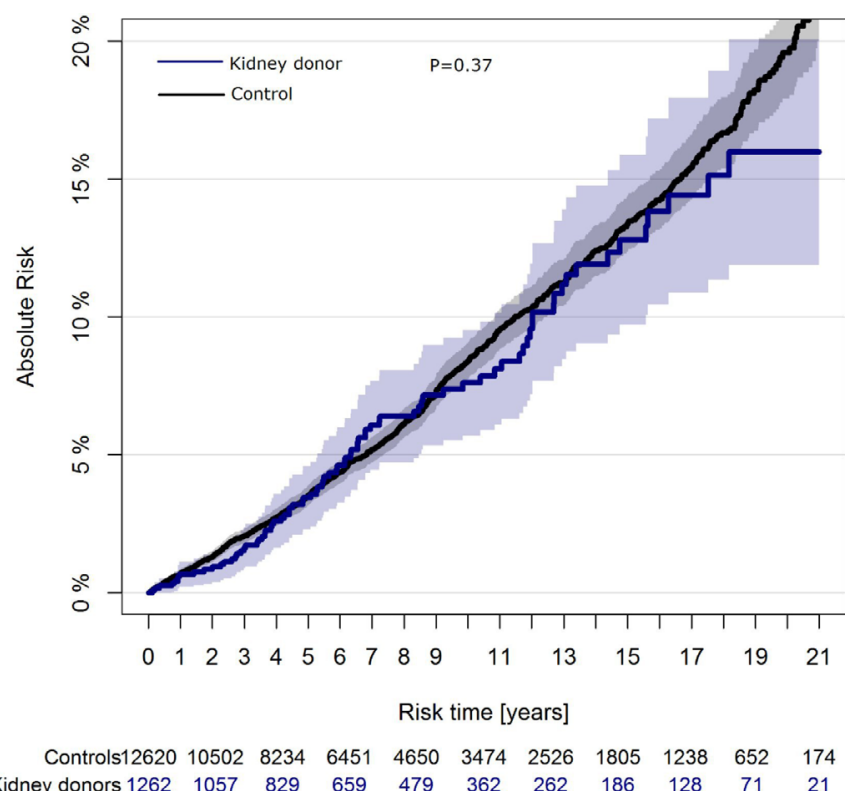

Figure 3 Absolute risks of cardiovascular disease after living kidney donation. * $P$ value indicates the difference in absolute risks by Gray's test. 


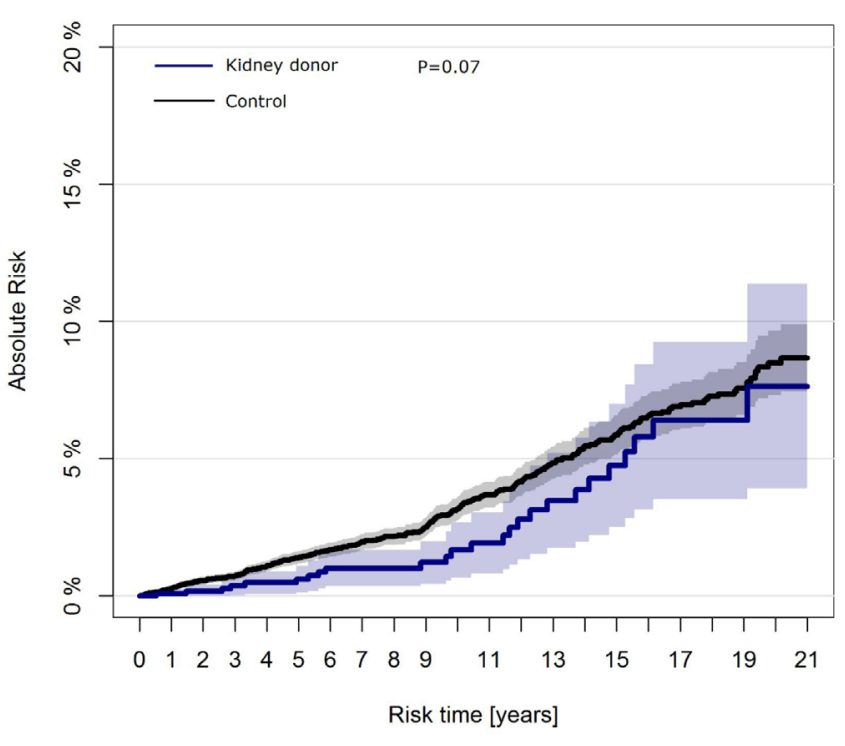

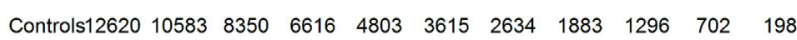

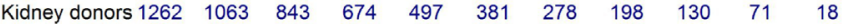

Figure 4 Absolute risks of diabetes after living kidney donation. ${ }^{*} \mathrm{P}$ value indicates the difference in absolute risks by Gray's test.

a single centre and presented from self-reported surveys a prevalence of hypertension in $4 \%$ and $10 \%$ at 5 and 10 years, respectively. ${ }^{9}$ The study was subjected to information bias and had incomplete data on hypertension at baseline and follow-up in $17.4 \%$ of the studied population. Likewise, Ibrahim et al reported hypertension in $32.1 \%$ at mean 12.2 years in a study population of 255 (7\% of all living kidney donations in the study period) living kidney donors during the period 1963-2007 at a single centre. ${ }^{3}$ However, this study included only living kidney donors who were alive at the conduction of the study and with accessible contact information. In a small cohort including 21 living kidney donors, Lenihan et al observed hypertension in 57\% living kidney donors at median, 6.1 years. ${ }^{11}$ The study was small and had a short follow-up period. Hence, previous studies are characterised by limited generalisability, incomplete baseline or

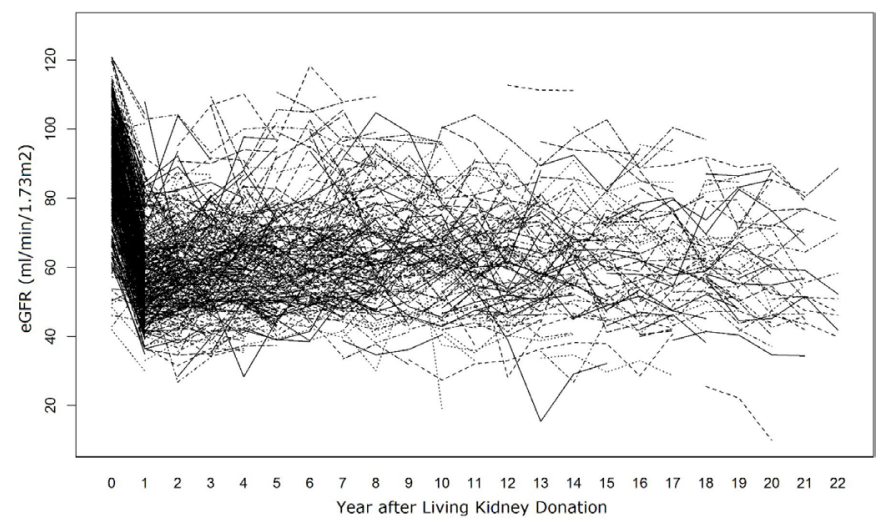

Figure 5 eGFR measurements of the living kidney donor population after kidney donation. Values are indicated when available with lines drawn between observations for each individual. eGFR, estimated glomerular filtration rate. follow-up data on hypertension and subjected to information bias.

In a retrospective study of living kidney donors, Ekholm et al reported a lower risk of end-stage renal disease in living kidney donors than the general population. ${ }^{5}$ The study included 1112 living kidney donors during 19652005. Of these, six patients developed end-stage renal disease 16-27 years after kidney donation in an age range of 73-89 years except from one, who developed end-stage renal disease 14 years after donation at an age of 45 years related to renal carcinoma. On contrary, the results from Mjøen $e t a t^{4}$ and Muzaale et $a t^{6}$ indicated an increased risk of end-stage renal disease in living kidney donors as compared with their healthy matched controls. However, neither study could match their controls for baseline factors as time of inclusion or location as end-stage renal disease in fact is partly related to the environment. The present study found a low frequency of renal replacement therapy requiring end-stage kidney disease in living kidney donors as well as in controls.

The majority of living kidney donors was in a combination treatment with renin-angiotensin system inhibitors for hypertension in the present study, which is in line with current guidelines for treatment of hypertension. ${ }^{20}$

The prevalence of diabetes and cardiovascular disease were consistent with the previous literature. ${ }^{9}$

In a retrospective case series, Okamoto et $a l^{7}$ studied 601 living kidney donors through 1970-2006 at a single centre. The distribution of malignancy as cause of death in living kidney donors during follow-up was comparable to our present data.

\section{CONCLUSION}

The long-term absolute risk of hypertension is increased in living kidney donors compared with the matched controls from the general population. No significant difference was observed for cardiovascular disease and diabetes between living kidney donors and controls.

Contributors MC and CT-P conceived and designed the study. MC and CT-P performed the statistical analyses. MC wrote the first version of the manuscript. MC, GHG, ELF, LK, TAG, CT-P interpreted the results, edited and approved the final version of the manuscript. The corresponding author attests that all listed authors meet authorship criteria and that no others meeting the criteria have been omitted.

Funding The authors have not declared a specific grant for this research from any funding agency in the public, commercial or not-for-profit sectors.

Competing interests None declared.

Patient consent for publication Not required.

Ethics approval The present observational study was registered at The Danish Data Protection Agency (ref. 2007-58-0015 / internal ref. GEH-2014-015 I-suite no. 02733). Ethical approval is not required for observational studies in Denmark. Work with nationwide data requires that individuals are protected. Part of this requirement is that data on one to three individuals are not disclosed. Therefore such numbers are presented as ' $\leq$ '.

Provenance and peer review Not commissioned; externally peer reviewed.

Data availability statement Data are available upon reasonable request. Data may be obtained from a third party and are not publicly available. The data that support the findings of this study are available from Statistics Denmark, but restrictions apply to the availability of these data, which were used under license 
for the current study, and so are not publicly available. Data are however available from the authors upon reasonable request and with permission of Statistics Denmark.

Supplemental material This content has been supplied by the author(s). It has not been vetted by BMJ Publishing Group Limited (BMJ) and may not have been peer-reviewed. Any opinions or recommendations discussed are solely those of the author(s) and are not endorsed by BMJ. BMJ disclaims all liability and responsibility arising from any reliance placed on the content. Where the content includes any translated material, BMJ does not warrant the accuracy and reliability of the translations (including but not limited to local regulations, clinical guidelines, terminology, drug names and drug dosages), and is not responsible for any error and/or omissions arising from translation and adaptation or otherwise.

Open access This is an open access article distributed in accordance with the Creative Commons Attribution Non Commercial (CC BY-NC 4.0) license, which permits others to distribute, remix, adapt, build upon this work non-commercially, and license their derivative works on different terms, provided the original work is properly cited, appropriate credit is given, any changes made indicated, and the use is non-commercial. See: http://creativecommons.org/licenses/by-nc/4.0/.

\section{ORCID iD}

Mavish Chaudry http://orcid.org/0000-0002-7726-0084

\section{REFERENCES}

1 Barry JM. Successful homotransplantation of the human kidney between identical twins. 1956. J Urol 2002;167:830.

2 Cohen DJ, St Martin L, Christensen LL, et al. Kidney and pancreas transplantation in the United States, 1995-2004. Am J Transplant 2006;6:1153-69.

3 Ibrahim HN, Foley R, Tan L, et al. Long-term consequences of kidney donation. N Engl J Med 2009;360:459-69.

4 Mjøen G, Hallan S, Hartmann A, et al. Long-term risks for kidney donors. Kidney Int 2014;86:162-7.

5 Fehrman-Ekholm I, Nordén G, Lennerling A, et al. Incidence of end-stage renal disease among live kidney donors. Transplantation 2006;82:1646-8.

6 Muzaale AD, Massie AB, Wang M-C, et al. Risk of end-stage renal disease following live kidney donation. JAMA 2014;311:579.
7 Okamoto M, Akioka K, Nobori S, et al. Short- and long-term donor outcomes after kidney donation: analysis of 601 cases over a 35-year period at Japanese single center. Transplantation 2009;87:419-23.

8 Segev DL, Muzaale AD, Caffo BS, et al. Perioperative mortality and long-term survival following live kidney donation. JAMA 2010;303:959-66.

9 Sanchez OA, Ferrara LK, Rein S, et al. Hypertension after kidney donation: incidence, predictors, and correlates. Am J Transplant 2018;18:2534-43.

10 Garg AX, Prasad GVR, Thiessen-Philbrook HR, et al. Cardiovascular disease and hypertension risk in living kidney donors: an analysis of health administrative data in Ontario, Canada. Transplantation 2008;86:399-406.

11 Lenihan CR, Busque S, Derby G, et al. Longitudinal study of living kidney donor glomerular dynamics after nephrectomy. J Clin Invest 2015;125:1311-8.

12 Holscher CM, Haugen CE, Jackson KR, et al. Self-reported incident hypertension and long-term kidney function in living kidney donors compared with healthy Nondonors. Clin J Am Soc Nephrol 2019;14:1493-9.

13 Boudville N, Prasad GVR, Knoll G, et al. Meta-Analysis: risk for hypertension in living kidney donors. Ann Intern Med 2006;145:185.

14 Lynge E, Sandegaard JL, Rebolj M. The Danish national patient register. Scand J Public Health 2011;39:30-3.

15 Thygesen SK, Christiansen CF, Christensen S, et al. The predictive value of ICD-10 diagnostic coding used to assess Charlson comorbidity index conditions in the population-based Danish national Registry of patients. BMC Med Res Methodol 2011;11:83.

16 Rasmussen L, Valentin J, Gesser KM, et al. Validity of the prescriber information in the Danish national prescription registry. Basic Clin Pharmacol Toxicol 2016;119:376-80.

17 Helweg-Larsen K. The Danish register of causes of death. Scand J Public Health 2011;39:26-9.

18 Olesen JB, Lip GYH, Hansen ML, et al. Validation of risk stratification schemes for predicting stroke and thromboembolism in patients with atrial fibrillation: nationwide cohort study. BMJ 2011;342:d124.

19 Hommel K, Rasmussen S, Madsen M, et al. The Danish registry on regular dialysis and transplantation: completeness and validity of incident patient registration. Nephrol Dial Transplant 2010;25:947-51.

20 Bech JN. Hypertensio arterialis-behandlingsvejledning, 2015. Available: http://www.dahs.dk/fileadmin/user_upload/ 2013opdateringer/opdateringer2014/opdateringer2015/behandlingsv ejledning2015junifinal.pdf [Accessed 30 Sep 2019]. 